OPEN ACCESS

UNIVERSITY OF THE

WEST of SCOTLAND

UWS Academic Portal

\title{
A comparison of activity levels of girls in single-gender and co-ed physical education
}

Wallace, Laura; Buchan, Duncan; Sculthorpe, Nicholas

Published in:

European Physical Education Review

DOI:

$10.1177 / 1356336 \times 19849456$

Published: 01/02/2020

Document Version

Peer reviewed version

Link to publication on the UWS Academic Portal

Citation for published version (APA):

Wallace, L., Buchan, D., \& Sculthorpe, N. (2020). A comparison of activity levels of girls in single-gender and coed physical education. European Physical Education Review, 26(1), 231-240.

https://doi.org/10.1177/1356336X19849456

\section{General rights}

Copyright and moral rights for the publications made accessible in the UWS Academic Portal are retained by the authors and/or other copyright owners and it is a condition of accessing publications that users recognise and abide by the legal requirements associated with these rights.

Take down policy

If you believe that this document breaches copyright please contact pure@uws.ac.uk providing details, and we will remove access to the work immediately and investigate your claim. 
Reprinted by permission of SAGE Publications. 


\section{Abstract:}

2 This study examined whether single-gender or mixed-gender PE lessons were more conducive to increasing the physical activity levels of girls. One hundred and twenty

4 girls (12-15 years) wore an wGT3x+ActiGraph accelerometer while participating in

5 basketball games. Time spent in low (LPA), moderate (MPA), vigorous (VPA) and

6 moderate-to-vigorous physical activity (MVPA) were compared between a single-

7 gender and mixed-gender PE lesson. Perceived effort and enjoyment of each lesson

8 were also captured using a three-point scale following the intervention. Girls were

9 found to spend significantly more time in MVPA $(p=0.01)$ and VPA $(p=0.006)$ in the

10 single-gender environment. Furthermore, girls spent significantly less time in LPA

11 ( $p=0.014)$. Although girls believed that their effort did not alter with the addition of

12 boys, they did show a preference for taking part in a single-gender environment.

13 Results of this study suggest that segregating PE classes for game-based activities

14 could lead girls to achieve greater health benefits through a higher level of activity.

15 Key Words: females, physical activity, accelerometer, MVPA, enjoyment, mixed16 gender sports 


\section{Introduction}

Participation in physical activity has key benefits to children's physical and mental health through weight management, improved mood and stress control (Janssen and Le Blanc, 2010; Poitres et al., 2016; Strong et al., 2005). Early participation in sport can influence continuation into adulthood (Haerens, Kirk and Cardon, 2011; Kirk, 2005) which may address the issue of decreasing activity levels with age, and associated health problems. Current statistics show that worldwide people are not physically active enough to reap the health benefits (Hallal et al., 2012; WHO, 2018) with $81 \%$ of adolescents (age 11-17 years) reportedly failing to meet government guidelines of 60 minutes of moderate-to-vigorous physical activity (MVPA) per day $(\mathrm{WHO}, 2018)$. Furthermore, when considering girls specifically there is a marked difference in participation levels. According to World Health Organisation statistics, in most countries and regions worldwide, adolescent girls participate in significantly less physical activity than boys (Currie et al., 2012). Many reasons have been posited for this, including the competitive climate, a belief that it is not feminine, the influence of boys and lack of perceived competence in PE (Mitchell et al., 2015). Regardless of the reasons, insufficient levels of physical activity are likely to lead to future health problems, therefore adolescent girls have become a key target group for practitioners (Okley et al., 2017).

Schools are an environment where physical activity can be increased through unorganised playground activity (Colabianchi et al., 2009; Willenberg et al., 2010), and organised physical education (PE) lessons (Wang, 2018). However, a recent systematic review and meta-analysis investigating time spent in MVPA during school PE lessons suggests that secondary school students only spend on average $40.5 \%$ of 
1 PE lessons participating in MVPA (Hollis et al., 2017). Furthermore, studies have shown girls spend significantly less time than boys in MVPA in PE lessons (Kerr et al., 2018; Slingerland, Oomen and Borghouts, 2011; Smith et al., 2014). This difference in effort between genders, coupled with the knowledge that for many girls PE is the only time they partake in any form of physical activity (McKenzie and Lounsbery, 2009; Westerstahl et al., 2005), suggests the area warrants further investigation. This may allow practitioners to implement more evidence-based strategies to increase the activity levels of girls in PE. Qualitative research has suggested that adolescent girls often prefer single-gender classes in PE (Hills and Croston, 2012; Slingerland et al., 2013; Timkin, McNamee and Coste, 2019) and further investigations have suggested that the effort levels of girls are increased when there are no boys present (Liukkonen et al., 2010; Lyu and Gill, 2011; Taylor et al., 2010); however these findings are limited by their subjective assessment of MVPA.

Findings of the only previous study to use a device-based measurement of effort to compare girls' heart rate (HR) response in single-gender and mixed-gender basketball games found no significant differences in HR response between the two environments (Slingerland et al., 2013). The authors did however find that girls' perceived competence increased in the single-gender environment. This finding is of significance as there is often a relationship between perceived competence and effort (Knowles et al., 2009; Lyu and Gill, 2011; Taylor et al., 2010). Nonetheless, there are several noteworthy limitations associated with the study design used by Slingerland and colleagues that limit the interpretation of their findings. For instance, although girls played in single-gender games, boys remained in the class playing on adjacent courts who were able to watch them play. Moreover, all girls took part in mixed-gender games in week one and single-gender games in week two; therefore any changes in activity 
1 in week two because of increased competence may be as a result of their participation

2 in the activity in week one.

3 In light of these limitations, the aim of the present study was to compare MVPA levels

4 in single-gender and mixed-gender PE classes using a crossover design. A 5 subsequent aim was to examine whether the presence or absence of boys impacted 6 upon girls' perceived effort during PE, and session preference. Correspondingly our 7 hypotheses were:

1. Girls will spend more time in MVPA in a single-gender session, in comparison with a mixed-gender session.

2. Girls will show a preference for single-gender PE lessons.

\section{Methodology}

\section{$\underline{\text { Participants }}$}

This study took place in one secondary school in the West of Scotland. The school is based in an urban area and accommodates around 1200 children aged 1118 years. This school was chosen as a result of an existing relationship between the lead researcher and PE staff. Although only one school was sampled, this school has five feeder primary schools, varying in rankings in the Scottish Index of Multiple Deprivation (SIMD) (Scottish Government, 2016), making it reflective of the majority of the local population. Stage sampling was used to select girls from S2-S4 (aged 1215 years) during core PE lessons. Participants were recruited from five classes during their standard PE time. Parental consent forms and assent forms were distributed to 
1 all pupils in these classes (137 in total) along with information sheets. Approval was

2 granted by the University of the West of Scotland Research Ethics Committee.

3

4

5

6

7

8

9

\section{Procedure}

Participants took part in two basketball sessions (one week apart) during timetabled core PE lessons. At the time of the study basketball was already being taught as part of the curriculum, therefore the girls were familiar with the game and were able to participate fully without the need for additional preceding sessions.

\section{Data Collection}

During the two lessons the girls wore a GT3X+ ActiGraph accelerometer at the hip for the duration of the class. The girls all fitted the devices themselves at the start of each lesson. To ensure accuracy of recording the lead researcher undertook a detailed demonstration and girls were all required to show her the positioning of their device before starting to play. A collection rate of 100 Hertz was used and results were downloaded in one second epochs. The low frequency extension was not applied. Evenson cut-off points were used (Evenson et al., 2008) to signify periods of sedentary behaviour, light physical activity (LPA), moderate physical activity (MPA) and vigorous physical activity (VPA). These cut-points were chosen as these have been shown to provide acceptable classification accuracy (Trost et al., 2011).

The basketball sessions were led by the pupils' usual PE teacher. To avoid the influence of teaching style the teachers were briefed prior to the commencement of the study and instructed to simply set up the games and enforce rules, but not to provide any encouragement or feedback. The teachers were also given a schedule to stick to exactly to standardise timings between sessions. A researcher was present 
1 throughout all sessions to aid the pupils when fitting the accelerometers, and also to

2 keep timings of games to ensure continuity. All games started and finished at exactly

3 the same time. After allowing time for the pupils to change, fit the accelerometers and

4 organise playing teams, the 30 -minute lesson time resulted in 20 minutes of actual

5 game time; five-minute games, separated by one-minute recovery. All data collected

6 before the first game started, after the last game ended, and during rest periods were

7 deleted prior to analysis. The researcher's watch was synced to the computer which

8 initialized the accelerometers to allow accurate removal of break time from the 9 analysis.

For the lessons, the participants were divided into two random groups. In the first session group A took part in mixed-gender games and group B took part in singlegender games. To ensure they were completely separate the games hall was sectioned off with a heavy curtain, therefore no pupils were aware of what was going on in the other area. In the second session the situations were reversed with group A taking part in the single-gender games and group B in mixed-gender.

Following the intervention participants were given a questionnaire that asked them to report their lesson preference on a three-point scale (single gender, mixedgender, or no preference) alongside which they were encouraged to add any comments they wished to explain their reasons. Additionally, they were asked to rate their perceived effort level when boys were present, again on a three-point scale (work harder, work less hard, or put in the same effort), along with an opportunity to provide reasons. These scales and associated comments were completely anonymous and were completed independently by the participants. 
2 Test was used to compare differences between activity levels in the two PE lessons.

3 All analyses were conducted using IBM SPSS Statistics v.23 (IBM, Armonk, NY). For

4 all analyses, statistical significance was set at $P<0.05$. Effect size (ES) statistics were

5 also established based on Cohen's $(d)$ classifications: small $(0.2 \leq d<0.5)$, moderate

$6 \quad(0.05 \leq d<0.8)$, and large $(d \geq 0.8)$ ES (Cohen, 1988). For perceived effort and lesson

7 preference percentages were calculated from the three options for each completed

8 scale; indicating how many girls chose each response. Finally, content analysis

9 (Cavanagh, 1997) was utilised to code data into themes based around the study's

10 hypotheses.

Results

From the 137 pupils who were approached to participate in the study, 128 returned consent and assent forms, and were included in the study. Table 1 shows descriptive statistics for year groups. There were eight pupils absent from school for either one or both sessions; therefore these participants were removed prior to analysing the data, leaving a final sample of 120 (age $14 \pm 2$ years). 
1 Table 1. Descriptive characteristics of girls by year group

Year group Number of girls

S2 46

S3

49

S4

33

Total

128

Figure 1 shows the amount of time girls spent in the different activity levels

4 between the two class situations. Girls spent significantly more time in MVPA in the

5 single-gender session compared to the mixed-gender session (17.03 \pm 2.64 min vs.

$6 \quad 15.62 \pm 4.25 \mathrm{~min} ; d=0.40, P=0.01$ ). The girls also spent significantly more time in

$7 \quad$ VPA in the single-gender session compared to the mixed-gender session $(11.45 \pm 5.33$

$8 \quad \min$ vs. $9.43 \pm 5.63 \mathrm{~min} ; d=0.37, P=0.006)$ and significantly less time in LPA (2.98

$9 \quad \pm 2.62 \mathrm{~min}$ vs. $4.38 \pm 4.37 \mathrm{~min} ; d=0.39 P=0.014)$. 


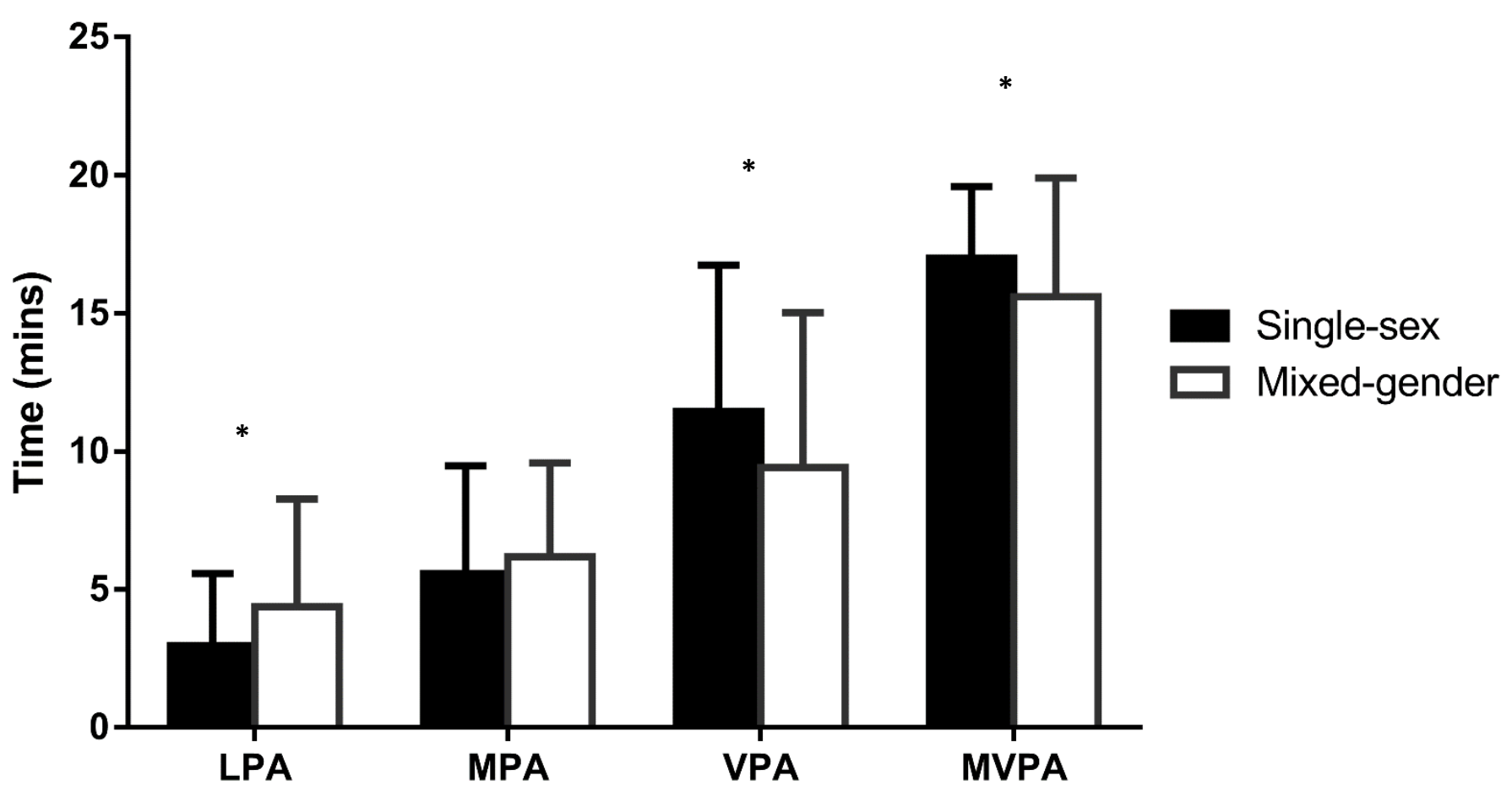

2 Figure 1. Time spent in each level of activity. LPA = low physical activity, MPA = 3 moderate physical activity, VPA $=$ vigorous physical activity, MVPA $=$ moderate4 vigorous physical activity. ${ }^{*} P<0.05$

In terms of preference, a slight majority of girls stated that they favoured single-

7 gender activities ( $n=66,55 \%)$, with only 12 girls (10\%) stating a preference for mixed8 gender. The remaining 42 girls (35\%) had no preference. Table 2 summarises the 9 most common reasons in relation to this preference. 
1 Table 2. Reasons given by participants for preference of single-gender activities

\begin{tabular}{ll}
\hline Theme & Number of girls \\
\hline Embarrassment / body image & 20 \\
Boys 'taking over'/ not passing & 23 \\
Intimidation & 14 \\
Confidence & 11 \\
Perceived competence & 8 \\
Competitive climate & 5 \\
Friendships & 5 \\
\hline
\end{tabular}

2

In terms of perceived effort, 19 girls (16\%) stated that they put in more effort

4 when boys were present. The majority believed that their effort did not change $(n=71$, $559 \%)$, however $30(25 \%)$ of the girls said that they were likely to put in less effort when

6 boys were present; with common reasons provided in table 3 . Where girls believed

7 their effort did not change their reason was generally, "why should it?" In those that

8 felt they worked harder when boys were in class they stated factors such as "more

9 competition" and "more of a challenge" as they perceived boys' ability levels to be

10 greater. This finding is worthy of note as it suggests that for some girls a single-gender class may in fact hinder their activity levels. 
1 Table 3. Reasons for decreased effort in mixed-gender activities

\begin{tabular}{ll}
\hline Theme & Number of girls \\
\hline Boys taking over & 12 \\
Embarrassment & 11 \\
Intimidation & 10 \\
Perceived Competence & 5 \\
Lack of confidence & 4 \\
\end{tabular}

2

3 Discussion

The main findings of this study are that girls are significantly more active, and 5 enjoy basketball more, in a single-gender PE class.

\section{$6 \quad$ Activity Levels}

During the study girls spent significantly more time in MVPA when playing in a 8 single-gender environment. This supports the findings of a similar study by Smith, Lounsbery and McKenzie (2014) in which PE lessons were observed, and activities monitored and compared, between different class settings (including single-gender and mixed-gender). The study by Smith, Lounsbery and McKenzie (2014) measured types of activities undertaken throughout lessons by observation. The current study arguably provides more objective data about activity levels through the use of accelerometers. Furthermore, the current study utilised a crossover design in order to limit the influence of confounding variables. As Smith and colleagues' (2014) study observed completely different classes (in different schools) there is a possibility that 
1 the variation in activity levels could be a result of different fitness levels and/or attitudes

2 towards PE by the different pupils. With a random crossover design, each participant took part in both sessions; therefore, discrepancies in activity levels cannot be attributed to individual differences.

Another interesting finding is that time spent in VPA was significantly increased in the single-gender environment, with no significant difference in MPA between the conditions. MVPA can increase with changes to either MPA or VPA, and in this case it was entirely driven by increased time in VPA. As this is the domain in which most health benefits occur (Janssen and Le Blanc, 2010; Schwarzfischer et al., 2017) this finding should be of real significance to practitioners. Studies have shown that for many adolescent girls, PE is the only time that they undertake any form of physical activity (McKenzie and Lounsbery, 2009; Westerstahl et al., 2005), therefore if higher activity levels can be raised within these sessions the impact upon health may be substantial.

Findings in the current study contrast with another previous study which found no significant difference in actual activity levels between single-gender and mixedgender basketball games in PE (Slingerland et al., 2013). Although device-based measures of PA were used in both, the discrepancy in findings may be due to the key difference in the studies' designs. For instance, In Slingerland and colleagues' (2013) study, although the basketball games observed were single-gender, boys remained present in the class and could observe the girls whilst participating in their session. As previous studies have inferred that girls' lack of activity can be attributed to feelings of embarrassment and intimidation when boys are watching them (Casey et al., 2009), it is reasonable to assume that this could be the reason for the different findings evident 
1 between Slingerland and colleagues to that of our own. Nonetheless, further work is

2 necessary to confirm our initial assertions. Our findings are also in contrast to those reported by McKenzie et al. (2004) who found that girls actually had higher activity levels in mixed-gender classes. However, like the study by Smith, Lounsbery and McKenzie (2014), McKenzie et al. (2004) observed different groups of students in a range of PE lessons, thus it cannot be ruled out that there were other confounding variables involved in the findings such as different fitness levels, attitudes towards sport, and the activity offered by the teacher, in each class. These conflicting findings, however, suggest that further, more extensive, studies should be undertaken to provide more conclusive evidence.

\section{$\underline{\text { Perceived effort }}$}

When asked about perceived effort most girls stated that their effort did not alter with the introduction of boys to the class. This contrasts with previous studies in which girls have admitted to avoiding activity in the presence of boys (Casey et al., 2009; Moe, 2006). However, when analysing the accelerometer data, it did not appear to support the participants' perceptions that their effort did not alter. The use of accelerometers to capture activity levels is a strength of this study and highlights the disparity between perceived, and actual, intensity of activity. Moreover, with the majority (59\%) of girls stating that their effort did not alter between the conditions, when in fact in many cases it did, this provides further evidence of the limitations of using self-reporting questionnaires to measure effort. In the present study the girls appeared to be unaware that their effort changed between the conditions. This suggests that they did not deliberately work harder in the single-gender environment, but subconsciously became more involved in the activity when boys were removed. 
1 This is an important finding as previous interventions have tended to result from self-

2 reporting of activity and preference. Therefore, the results of the present study suggest that girls may not actually be aware of the effect that the presence of boys has on their activity levels in PE.

\section{$\underline{\text { Strengths and limitations }}$}

There are some key strengths and limitations to this study that should be acknowledged. Through using accelerometers to measure activity levels, we were able to provide a more objective analysis of the intensity of activity undertaken during each of the sessions. Previous studies tend to use observation tools such as SOFIT, and self-reporting questionnaires, which may fail to accurately capture the effort girls provide during their mixed-gender and single-gender sessions. Another strength of this study is in its crossover design which limits the possibility that any differences are related to the participants' individual characteristics, or increased competence in the activity, since all girls took part in both parts of the study. Collecting subjective feedback from the participants concerning effort is also a strength of this study which provided evidence of the disparity that may be evident between perceived and actual effort. In terms of limitations, firstly the study took place in one school in South Ayrshire, Scotland, which limits the generalisability of our findings. Secondly, due to access restrictions with the school, the study took place over a short period of time. With just a single, acute change to PE delivery, it is not clear whether increased MVPA would be apparent following a longer-term intervention. Thirdly, this study presents findings only in relation to modified basketball games. Since PE includes a wide range of activities including individual sports such as racket sports and less traditional 
1 physical activities such as dance and aerobics, it is unclear whether the findings

2 reported here would be similar in these activities.

\section{Conclusion}

5 Overall, this study partially supports the findings of Smith, Lounsbery and 6 McKenzie (2014), suggesting that single-gender PE may be more appropriate for

7 maximising activity levels for adolescent girls within the school curriculum. Results of 8 this study show that girls spend significantly more time in MVPA and VPA in a single9 gender PE environment and that the majority prefer to take part in games when boys are not present. Future work may wish to further investigate actual effort levels of girls

11 in single-sex and mixed-gender environments, in a range of sports and activities, in order to confirm the findings reported herein. 


\section{$1 \quad$ References}

2 Casey MM, Eime RM, Payne WR and Harvey JT (2009) Using a Socioecological

3 Approach to Examine Participation in Sport and Physical Activity Among Rural

$4 \quad$ Adolescent Girls. Qualitative Health Research 19(7): 881-894.

5 Cavanagh S. (1997) Content Analysis: Concepts, Methods and Applications. Nursing

6 Research 4(3): 5-16.

7 Cohen J. (1988) Statistical power analysis for the behavioral sciences. Hillsdale, NJ:

$8 \quad$ L. Erlbaum Associates.

9 Colabianchi N, Kinsella AE, Coulton CJ and Moore, SM (2009) Utilization and

10 Physical Activity Levels at Renovated and Unrenovated School Playgrounds.

11 Preventative Medicine 48: 140-143.

12 Currie C, Zanotti C, Morgan A, Currie D, De Looze M, Roberts C, Samdal O, Smith

13 ORF and Barnekow V (eds) (2012) Social Determinants of Health and Well-being

14 among Young People. Health Behaviour in School-aged Children (HSBC) Study:

15 International Report from the 2009/10 Survey. Copenhagen: World Health

16 Organisation.

17 Evenson KR, Catterllier D, Gill K, Ondrak K and McMurray RG (2008) Calibration of

18 Two Objective Measures of Physical Activity for Children. Journal of Sports Science 26: 1557-1565.

Haerens L, Kirk D and Cardon G. (2011) Toward the Development of a Pedagogical Model for Health-based Physical Education. Quest 63: 321-338. 
1 Hallal PC, Bo Andersen L, Guthold R, Haskell W and Ekelund U (2012) Global

2 Physical Activity Levels: Surveillance Progress, Pitfalls, and Prospects. The Lancet 380(9838): 247-257.

Hills L and Croston A (2012) 'It Should be Better All Together': Exploring Strategies for 'Undoing' Gender in Coeducational Physical Education. Sport, Education and Society 17(5): 591-605.

Hollis J, Sutherland R, Williams AJ, Campbell E, Nathan N, Wolfenden L, Morgan

PJ, Lubans DR, Gillham K, and Wiggers J (2017) A Systematic Review and Metaanalysis of Moderate-to-Vigorous Physical Activity Levels in Secondary School Physical Education Lessons. International Journal of Behavioral Nutrition and Physical Activity 14(52): 1-26.

Janssen I and Le Blanc AG (2010) Systematic Review of the Health Benefits of Physical Activity and Fitness in School-aged Children and Youth. International Journal of Behavioural Nutrition and Physical Activity 7(40): 1-16.

Kerr C, Smith L, Charman S, Harvey S, Savory L, Fairclough S and Govus A (2018) Physical Education Contributes to Total Physical Activity Levels and Predominantly Review 24(2): 152-164.

Kirk D (2005) Physical Education, Youth Sport and Lifelong Participation: The Importance of Early Learning Experiences. European Physical Education Review 11(3): 239-255. Examination of the Influence of Maturation on Physical Self-Perceptions and the 
1 Relationship with Physical Activity in Early Adolescent Girls. Journal of Adolescence

$2 \quad 32(3): 555-566$

3 Liukkonen J, Barkoukis V, Watt A and Jaakkola T (2010) Motivational Climate and

4 Students' Emotional Experiences and Effort in Physical Education. The Journal of

$5 \quad$ Educational Research 103: 295-308.

6 Lyu M and Gill D (2011) Perceived Physical Competence, Enjoyment and Effort in

7 Same-Sex and Coeducational Physical Education Classes. Educational Psychology

$8 \quad 31(2): 247-260$

9 McKenzie TL and Lounsbery MAF (2009) School Physical Education: The Pill Pot

10 Taken. American Journal of Lifestyle Medicine 3(3): 219-225.

McKenzie TL, Prochaska J, Sallis J and McMaster K (2004) Coed and Single-sex

Physical Education in Middle Schools: Impact on Physical Activity. Research Quarterly for Exercise and Sport 74(4): 446-449.

Mitchell F, Inchley J, Fleming J and Currie C (2015) A Socio-ecological Approach to

Understanding Adolescent Girls' Engagement and Experiences in the PE

Environment: A Case Study Design. Graduate Journal of Sport, Exercise and

Physical Education Research 3: 44-62.

Moe SG, Pickrel J, McKenzie TL, Strikmiller PK, Coombs, D and Murrie D (2006)

Using School-Level Interviews to Develop a Multisite PE Intervention Program. Health Education and Behavior 33(1): 52-65.

Okley AD, Lubans DR, Morgan PJ, Cotton W, Peralta L, Miller J, Batterham M and Janssen X (2017) Promoting Physical Activity Among Adolescent Girls: The Girls in 
1 Sport Group Randomized Trial. International Journal of Behavioural Nutrition and

2 Physical Activity 14(81): 1-13.

3 Poitres VJI, Gray CE, Borghese M, Carson V, Chaput JP, Janssen I, Katzmarzyk PT,

$4 \quad$ Pate RR, Gorber SC, Kho ME, Samson M and Tremblay MS (2016) Systematic

5 Review of the Relationships Between Objectively Measured Physical Activity and

6 Health Indicators in School-aged Children and Youth. Applied Physiology, Nutrition

7 and Metabolism 41: 197-239.

8 Schwarzfischer P, Weber M, Gruszfeld D, Socha P, Luque V, Escribano E,

9 Xhonneux A, Verduci E, Mariani B, Koletzko B and Grote V (2017) BMI and

10 Recommended Levels of Physical Activity in School Children. BMC Public Health

11 17(595).

Scottish Government (2016) Introducing the Scottish Index of Social Deprivation 2016. Edinburgh: Scottish Government.

Slingerland M, Haerens L, Cardon G and Borghouts L (2013) Differences in

Perceived Competence and Physical Activity Levels During Single-Gender Modified

Basketball Game Play in Middle School Physical Education. European Physical

17 Education Review 20(1): 20-35.

Slingerland M, Oomen JM and Borghouts LB (2011) Physical Activity Levels during

Dutch Primary and Secondary School Physical Education. European Journal of Sport Sciences 11(4): 249-257.

Smith NJ, Lounsbery MAF and McKenzie TL (2014) Physical Activity in High School Physical Education: Impact of Lesson Context and Class Gender Composition. Journal of Physical Activity and Health 11: 127-135. 
1 Strong WB, Malina RM, Blimkie CJ, Daniels SR, Dishman RK, Gutin B,

2 Hergenroeder AC, Must A, Nixon PA, Piyarnick JM, Rowland T, Trost S and Trudeau

3 F (2005) Evidence Based Physical Activity for School-age Youth. Journal of

$4 \quad$ Paediatrics 146(6): 732-737.

5 Taylor IM, Ntoumanis N, Standage M and Spray C (2010) Motivational Predictors of

6 Physical Education Students' Effort, Exercise Intentions, and Leisure-Time Physical

7 Activity: A Multilevel Linear Growth Analysis. Journal of Sport and Exercise

$8 \quad$ Psychology 32(1): 99-120.

9 Timkin G, McNamee J and Coste S (2019) 'It Doesn't Seem Like PE and I Love It!'

10 Adolescent Girls' Views of a Health Club Physical Education Approach. European

11 Physical Education Review 25(1): 109-124.

12 Trost SG, Loprinzi PD, Moore R and Pfeiffer KA (2011) Comparison of

13 Accelerometer Cut Points for Predicting Activity Intensity in Youth. Medicine and

14 Science in Sports and Exercise 43(7): 1360-1368.

Wang L (2018) Accelerometer-determined Physical Activity of Children During

Segmented School Days: the Shanghai Perspective. European Physical Education

Review. Epub ahead of print 3 June 2018. DOI: 10.1177/1356336X18776874.

Westerstahl M, Barnekow-Bergkvist M and Jansson E (2005) Low Physical Activity among Adolescents in Practical Education. Scandinavian Journal of Medicine and Science in Sports 15(5): 287-297.

Willenberg LJ, Ashbolt R, Holland D, Gibbs L, MacDougall C, Garrard J, Green JB and Waters E (2010) Increasing School Playground Physical Activity: a Mixed 
1 Methods Study Combining Environmental Measures and Children's Perspectives.

2 Journal of Science and Medicine in Sport 13(2): 210-216.

3 World Health Organisation (2018) Physical Activity. Available at:

4 https://www.who.int/news-room/facts-in-pictures/detail/physical-activity (Accessed 21

$5 \quad$ February 2019)

6 